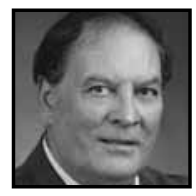

\title{
Commentary
}

\section{Mind, Brain, and Education: The Impact of Educational Neuroscience on the Science of Teaching}

David A. Sousa

\section{ABSTRACT}

Researchers have now acquired so much information about how the brain learns that a new academic discipline has been born, called "educational neuroscience" or "mind, brain, and education science." This field explores how research findings from neuroscience, education, and psychology can inform our understandings about teaching and learning, and whether they have implications for educational practice. This interdisciplinary approach ensures that recommendations for applying these findings to instructional practices have a foundation in solid scientific research. It also ensures that teachers are working smarter, not harder. This article discusses some of those exciting applications.

will never forget a visit I once made to a geometry class in an urban high school. The teacher-let's call her Mrs. Green-was expecting me and, after a brief greeting, she turned to the students and said, "Everybody up. Follow me." She grabbed a boom box as she went out the door, leaving the students somewhat puzzled. Like the Pied Piper, Mrs. Green led the class down to a closed-off section of the gymnasium. Portions of the floor were marked with different lengths of masking tape that formed triangles. Mrs. Green divided the class into several groups, and asked them to measure the lengths of the tape by pacing them out while they clapped to the lively music coming from the boom box. After several trials, she asked them to discuss their measurements and determine if they could see any common relationship. In just 40 productive and engaging minutes, Mrs. Green had helped these 
students teach themselves that, in a triangle, $a^{2}+b^{2}=c^{2}$. Might this lesson have gone differently if everyone had stayed in the classroom and Mrs. Green said, "Everyone open your mathematics books to page 57. Today, I am going to teach you the Pythagorean Theorem."? No doubt.

In a conversation later in the day, Mrs. Green told me, "I cannot teach mathematics today the way I did just five years ago. These kids' brains learn differently, and I have to adjust my teaching strategies if I have any hope of being successful." She recognized that today's students come to school with different expectations, with a desire to participate in their learning, and with the recognition that school is just one-and certainly not the only-source of information. Her comments were also a recognition that research in cognitive neuroscience is providing exciting new insights into how the brain develops and learns. Because teachers are what I call "brain changers," they realize that the more they know about how the brain learns, the more likely they are to design creative and interactive lessons like Mrs. Green's, and to be more successful at helping their students achieve and succeed.

In the past two decades, researchers have acquired so much information about how the brain learns that a new academic discipline has been born. Called educational neuroscience or mind, brain, and education science, this fledgling field explores how research findings from neuroscience, education, and psychology can inform our understandings about teaching and learning, and whether they have implications for educational practice. These implications do not represent an "in-the-box program" or the "strategy du jour" that teachers sometimes view with a wary eye. Rather, the goal of educational neuroscience is to reflect on this research and decide whether it should have an impact on educational practices. This interdisciplinary approach ensures that recommendations for teaching practices have a foundation in solid scientific research. It also ensures that teachers are working smarter, not harder.

As research continues to provide a deeper understanding of the workings of the human brain, educators should be excited yet cautious about how they apply these findings to practice. There are critics who believe that educators should not be using brain research at this time in schools and classrooms because it will be years before this research has any application to educational practice. Others fear that unsubstantiated claims are being made, usually referred to as "neuromyths," and that educators are not sufficiently trained to tell scientific fact from hype. They often refer, for example, to the notion that students can be just "left-brained" or "right-brained," or that we only use about 15 percent of our brain. Although the concerns are understandable, if outdated, they should not prevent educators from learning what they 
need to know to decide whether research findings have application to their practice. Furthermore, many educators have now become very aware of the neuromyths, so it is time for the critics to move on.

\section{Some Important Findings}

For those who wonder how recent discoveries about the brain can affect teaching and learning, here are a few of the research findings and their implications:

- Reaffirmed that the human brain continually reorganizes itself on the basis of input. This process, called neuroplasticity, continues throughout our life, but is exceptionally rapid in the early years.

Implication: The experiences the young brain has in the home and at school help shape the neural circuits that will determine how and what that brain learns in school and later in life.

- Startled the scientific world with evidence that neurons in the brain do regenerate, a process called neurogenesis (Deng, Aimone, \& Gage, 2010). Implication: Regenerating neurons enhance learning and memory. It seems that physical exercise, in part, stimulates neurogenesis. Yet time for recess and play is paradoxically being curtailed in many elementary schools to provide more study time for high-stakes testing. Does this make sense? We should ensure that students get adequate exercise every day to keep the brain primed with fuel, alert, and ready to learn.

- Challenged the notion that the brain can multitask. The brain can focus on only one task at a time. What is mistakenly called "multitasking" is really alternate tasking, that is, the brain shifting its attention from one task to a second task, and then back to the first one.

Implication: Each shift of the brain's attention requires increased mental effort and incurs a loss of information in working memory of the first task. In effect, the individual ends up doing two tasks poorly rather than one task well. Although using a variety of strategies in the classroom keeps students engaged, the shift from one activity to another should not be done before the first task is adequately learned.

- Revealed more about how the brain acquires a second language. This research dispels the myth that young students (less than 12 years old) learning a second language causes interference with the learning of their first language (Kovelman, Baker, \& Petitto, 2008). In reality, the reverse is true. 
Implication: Learning two languages simultaneously is no problem for the young brain's language processing networks, and it helps the learners grasp the deeper structure of languages. Start instruction in a new language as early as possible because learning a new language requires more mental effort and motivation after the age of 12 years.

- Discovered the brain pathways involved in reading. Brain scans helped researchers discover that good readers use different neural pathways while reading than struggling readers (Shaywitz, 2003).

Implication: This research led to the development of scientifically based computer programs, such as Fast ForWord and Earobics, that dramatically help young children with reading problems. In effect, these programs rewire the young brain of struggling readers (thanks to neuroplasticity) to more closely resemble the neural wiring of good readers.

- Updated our understandings about the capacity limits of working memory. Implication: Recent studies suggest that the capacity of working memorythat is, the number of items it can hold at any one time-is unexplainably decreasing from about seven items to about five. Consequently, teachers should be presenting fewer items in each lesson and asking students to discuss them in more detail so that they are likely to remember them. In other words, less is more. This is no easy task because the amount of information in school curriculums seems to be constantly increasing. Rather, we should be looking to delete items from the curriculum that are no longer relevant for a student to be successful in today's society, and use that time to delve deeper in those topics that are more meaningful.

- Shown how emotions affect learning, memory, and recall. Emotions alert the brain's attention systems, and experiences involving emotions are much more likely to be remembered.

Implication: Students learn better in schools and classrooms with a positive emotional climate-places where they are respected and where they feel the teachers really want them to succeed. They will also remember more of the curriculum content when it is linked with activities that evoke emotions.

- Recognized the critical role of movement and exercise in learning and memory. Researchers have discovered that movement and exercise increase the production of a vital substance called brain-derived neurotrophic factor, or BDNF (Ratey, 2008). This protein supports the survival of existing neurons, encourages the growth of new neurons, and is important for longterm memory formation. Furthermore, movement and exercise improve mood and enhance cognitive processing. 
Implication: Students sit too much in classrooms, especially in secondary schools and colleges. They should be up and moving during a lesson, and talking about what they are learning because talk, too, is a very effective memory device.

- Tracked the growth and development of the teenage brain.

Implication: Recognizing that the frontal lobe, or rational part of the teenage brain, takes about 22 to 24 years to fully develop, while the emotional parts of the brain develop in about 10 to 12 years. This significant difference in the maturity of brain regions helps us to better understand the unpredictability of adolescent behavior.

- Developed a deeper understanding of how circadian cycles affect focus. Implication: Knowing that our ability to focus naturally wanes for 30 to 45 minutes just past the middle of the day helps to explain why teaching and learning can be more difficult during that time. The research suggests that teachers should select instructional strategies that center around student engagement during this period to help maintain focus.

- Studied the effects of sleep deprivation and stress on learning and memory (Wilhelm et al., 2011).

Implication: Many students, especially in high school, come to school sleep deprived. Thanks to the temptations of technology and social media, they are averaging about five to six hours of sleep per night when then really need eight to nine hours. Persistent sleep deprivation triggers stress, and stress causes an increase in blood levels of the hormone cortisol. This hormone reduces one's ability to focus and impairs memory. Educators and parents need to remind students of the importance of getting adequate sleep.

- Recognized that intelligence and creativity are separate abilities that are not genetically fixed, and that both can be modified by the environment and schooling.

Implication: What educators do in schools can actually raise (or lower) a student's intelligence and creativity. The major problems facing our global society (e.g., overpopulation, supplies of adequate food and clean water, demand for energy, and climate change) will require creative solutions. Yet school curriculums do not place enough emphasis on developing creativity in their students. Students learn to be more creative through engagement and the authentic applications of their learning to real-world problems.

- Added to our knowledge of how the arts develop the brain.

Implication: Research studies are revealing how exposure to the arts can increase one's attention, spatial skills, and creativity. Too often, however, the 
arts are the first to suffer in schools when budgets get tight. Although too many people still regard the arts as frill subjects, brain research is showing that they are important contributors to the development of cognitive processing.

- Highlighted the degree to which a school's social and cultural climates affect teaching and learning.

Implication: We are only beginning to realize the impact that students' social needs have on learning. Research findings from the new field of social neuroscience are suggesting that schools need to give much more attention to students' social growth and focus also on the contributions that other cultures can make to teaching and learning.

This is truly an exciting time to be in education, thanks to the new information that educational neuroscience is providing. Several universities in North America and abroad have established dedicated research centers to examine how discoveries in neuroscience can affect educational practice. As a result, educational theory and practice will become much more research-based, similar to the medical model. There is, of course, no panacea that will make teaching and learning a perfect processand that includes brain research. It is a long leap from making a research finding in a laboratory to the changing of schools and practice because of that finding. We do not want to let the excitement cloud our common sense.

Never has society asked so much of its schools. At the same time, however, never have we known so much about how students learn and what we can do to make that happen successfully. Research in educational neuroscience opens the door in the hopes that educators will experience the joy of seeing more students reach their full potential. 


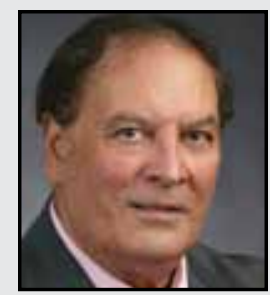

David A. Sousa is an international consultant in educational neuroscience and author of a dozen books that translate brain research into strategies for improving learning. He has presented to more than 100,000 educators across the United States, Canada, Europe, Australia, New Zealand, and Asia. He has taught high school chemistry, and served in administrative positions, including superintendent of schools. He was an adjunct professor of education at Seton Hall University and a visiting lecturer at Rutgers University.

Dr. Sousa has edited science books and published dozens of articles in leading journals. His books have been published in French, Spanish, Chinese, Arabic, Korean and several other languages.

\section{References}

Deng, W., Aimone, J. B., \& Gage, F. H. (2010). New neurons and new memories: How does adult neurocampal neurogenesis affect learning and memory? Nature Reviews Neuroscience, 11(5), 339-350.

Kovelman, I., Baker, S. A., \& Petitto, L-A. (2008, January). Bilingual and monolingual brains compared: A functional magnetic resonance imaging investigation of syntactic processing and a possible "neural signature" of bilingualism. Journal of Cognitive Neuroscience, 20, 153-169.

Ratey, J. (2008). Spark: The revolutionary new science of exercise and the brain. New York: Little, Brown.
Shaywitz, S. E. (2003). Overcoming dyslexia: A new and complete science-based program for reading problems at any level. New York: Knopf.

Wilhelm, I., Diekelmann, S., Molzow, I., Ayoub, A., Mölle, M., \& Born, J. (2011). Sleep selectively enhances memory expected to be of future relevance. The Journal of Neuroscience, 31, 1563-1569. 